\title{
O mundo do trabalho e a Educação Física: a formação em questão
}

\author{
Pítias Alves Lobo*
}

Tiago Onofre**

\section{Resumo}

Atualmente, o mundo do trabalho na Educação Física se divide em dois mundos: o escolar e o não escolar. Essa divisão reflete não só a necessidade de formaçôes diferentes demandadas pelos campos de intervenção, como também as modificaçóes que o próprio trabalho/trabalhador da área sofre no atual estágio de mudanças nas suas formas de organização. Como consequência, houve também uma divisão na nomenclatura do trabalhador para: licenciado (escolar) e graduado (não escolar) em Educação Física, que, embora tenham formaçôes e currículos diferenciados, seguem o mesmo paradigma, voltados para a construção de competências. Sendo assim, o texto buscou analisar a problemática da formação diante desse cenário fragmentado ao identificar em pesquisas recentes qual a centralidade da preocupação de pesquisadores com a temática da formação de professores. Buscou-se relacionar como o processo de reestruturaçáo produtiva influenciou a divisão do mundo do trabalho da área. Desse modo, após as nossas análises, propomos o resgate da ideia de uma formação ampla para um único mundo do trabalho, tendo o próprio trabalho enquanto princípio educativo, com o objetivo de superar, no processo de formação e intervençáo de seus professores, a possível tensão entre mundo do trabalho e Educação Física.

Palavras-chave: Educação Física, mundo do trabalho, formação de professores.

The world of work and Physical Education: formation under review

\footnotetext{
Abstract

The field of work in Physical Education is currently divided into two worlds: school and non-school. This division reflects not only the need for different types of formation demanded by the two different fields, but also the changes that the work/worker in the field

* Professor de Educação Física do Cepae/UFG. E-mail: pitiaslobo@hotmail.com

** Licenciado em Educação Física pela Faculdade de Educação Física (FEF/UFG) e mestrando em Educação Física pelo Programa de Pós-Graduação da Universidade de Brasília, (UnB). E-mail: tiagoonofre007@hotmail.com.
} 
suffers during the present phase of changes in their forms of organization. As a result, there has also been a division in the classification of the workers: those with a Licentiate (for schools) and non-school Physical Education graduates. Although they both have distinctive curricula and training, they follow the same paradigm in teacher formation centered on the acquisition of skills. Thus, the text set out to examine the issue of formation in the context of this fragmented scenario of the field by identifying in recent research what is the central concern of researchers when dealing with the theme of physical education teacher formation. It tried to report on how the productive restructuring process has influenced the classification of the world of work in the field. So as a result of our analysis, we propose to salvage the idea of a broad education for a single world of work, having the work itself as an educational principle of formation in Physical Education in order to overcome possible tensions between the workplace and Physical Education in the process of training and intervention of its teachers.

Keywords: physical education, world of work, teacher training.

\section{Introduçáo}

Lançar o olhar sobre o mundo do trabalho da Educação Física exige, além dos traços identificáveis aparentemente na sua divisão em mundos escolar e não escolar, identificar e compreender os elementos constitutivos dos processos de reestruturação e organização do trabalho e da produção da Educação Física nos últimos anos.

Aprofundar essa questão traz tarefas longe de serem fáceis: situar os modos de produção no sistema capitalista e sua recente reestruturação; situar em que sentido o processo educativo vem se modificando para responder às novas exigências por conhecimento e formação da classe trabalhadora; situar como tais políticas e demandas afetam diretamente o trabalho e a formação em Educação Física.

Além de compreender todos esses aspectos nos quais o mundo do trabalho da Educação Física e a formação de seus trabalhadores são diretamente influenciados pela atual conjuntura econômica, buscamos, de maneira inicial, resgatar os sentidos e os significados da intervenção da Educação Física sobre a educação do corpo e no trato dos conhecimentos relacionados à cultura corporal, tendo o trabalho na sua forma concreta situada em Marx, enquanto elemento constitutivo do homem e o seu princípio educativo.

Desse modo, o ensaio que aqui nos propusemos a fazer tem como objetivo geral refletir inicialmente a atualidade da relação entre o mundo 
do trabalho e Educação Física mediada pela formação de seus trabalhadores. Parte-se do princípio de que o mundo do trabalho constitui-se no lócus, ou natureza, no qual o professor irá intervir (trabalhar), e a Educação Física, como conjunto de conhecimentos e instrumentos culturalmente construídos e sistematizados pelos homens ao longo da história, em que,

desde as suas origens, percebemos que ela (campo) vem se constituindo, passo a passo, como teoria e prática fundada em diferentes ciências (biologia, antropologia, sociologia, psicologia, educação, química, física,...), de várias técnicas e a partir de valores culturais (linguagens, expressóes, gestos, símbolos...) circunscritas à cultura corporal (corporalidade humana) nas diferentes práticas e interesses determinados pelas distintas sociedades (especialmente ocidentais). (David, 2009, p. 7-8)

Ao centralizar o trabalho na formação dos trabalhadores (força de trabalho), buscamos identificar a possível tensão entre mundo do trabalho e educação física na relação produtor/produto nas atuais políticas de formação do trabalhador.

Para tanto, as sínteses aqui apresentadas partiram de uma revisão bibliográfica e o diálogo com os autores acerca dos temas que orientam a reflexão inicial sobre a realidade na formação de professores em Educação Física.

\section{A constituiçáo do mundo do trabalho e suas consequências para a Educação Física}

É insuficiente analisar a constituição do mundo do trabalho da Educação Física de forma desvinculada de um contexto geral. Se assim fosse feito, a identificação tampouco ultrapassaria as impressões e conclusôes imediatas a partir da aparência da problemática analisada.

O trabalho tem sofrido um reordenamento a partir da década de 1970. Essa mudança deu-se em função da crise de organização do capital, vigente até o referido período. Tínhamos antes, como referência, uma organização pautada no modelo taylorista-fordista, centrada na produção seriada e no trabalho manual com orientação técnico-instrumental, além de uma política econômica pautada no desenvolvimento estatal.

Com a crise de organização do capital, instaurada em meados da década de 1970, surge então uma nova configuração de suas bases material 
(reestruturação produtiva), econômica (globalização) e política (neoliberalismo), que modificam, assim, o papel do Estado, minimizado com relação ao gerenciamento e, principalmente, ao financiamento das políticas de direito público e maximizado em relação aos incentivos ao crescimento e à manutenção dos organismos privados (Kuenzer, 1998; Mészáros, 2006).

Nesse contexto,

o Estado moderno imensamente poderoso - e igualmente totalizador - se ergue sobre a base deste metabolismo socioeconômico que a tudo engole, e o complementa da forma indispensável (e não apenas servindo-o) em alguns aspectos essenciais. (Mészáros, 2006, p. 98)

$\mathrm{O}$ recuo do Estado influenciou da mesma forma o mundo do trabalho da Educação Física ao reduzir sua centralidade dentro da esfera pública. Esse fato proporcionou a expansão desses serviços pela iniciativa privada, e, em consequência, dos espaços não escolares da Educação Física. A esse respeito, pode-se mencionar, a título de exemplo, o crescimento, na década de 1980, das academias de ginástica, que se pautou nos princípios mercadológicos e administrativos da época até os dias atuais (Furtado, 2009).

Assim, novas formas de trabalhar a Educação Física foram emergindo ou se fortalecendo em acelerada expansão. Surge, então, a figura do bacharel, principalmente após a resolução n. 03/1987 do então Conselho Federal de Educação. Essa resolução não atingiu somente a Educação Física, mas todas as demais áreas ou disciplinas pedagógicas, pois dividiu esses cursos em áreas de bacharelado e de licenciatura. $\mathrm{O}$ argumento apontado para essa divisão foi a necessidade de formar novos profissionais para os campos que surgiram além do espaço escolar, pois a licenciatura não trabalhava com pesquisa, somente com o ensino, mostrando-se insuficiente para as demandas surgidas.

De modo diferente de outras áreas que seguiram a divisão bacharelado/licenciatura, os cursos de Educação Física optaram pela formação em licenciatura plena. Nessa titulação, encontravam-se as pesquisas e a formação, o que tornou injustificável a formação do bacharel. No entanto, em face da ampliação das possibilidades de intervenção (lazer, clubes, natureza, saúde, dança, academia, circo, turismo, etc.) e de discussóes realizadas na década de 1990, que, à luz da reorganização do processo produtivo, concluíram pela necessidade de introdução de uma formação específica na construção de competências para o espaço não escolar, foram elaboradas as Diretrizes Cur- 
riculares Nacionais, Resolução 07/2004 do Conselho Nacional de Educação, que dispôs sobre a formação em Educação Física na área de bacharelado.

Da divisão mencionada no parágrafo anterior, podem surgir diversos questionamentos. Não seria justamente essa separação de áreas o motivo do crescente desenvolvimento e investimento no trabalho não escolar da Educação Física e a redução ou até abandono do espaço escolar?

Essas indagaçóes podem ser ampliadas para os seguintes questionamentos: Quais foram as consequências para a formação em Educação Física nessa primeira década do século XXI? Como se dá o avanço dos cursos de Educação Física no Brasil, no número de licenciaturas e bacharelados? Em que medida a formação, no atual modelo, fragmenta a atuação do professor em intervençóes diferenciadas, dualizando os conhecimentos produzidos em Educaçâo Física?

Veremos, a seguir, como essa divisão no mundo do trabalho tem influenciado a formação, a organização legal, os modelos pedagógicos e o trabalho dos professores em formação.

\section{A formação em questão diante dos mundos do trabalho}

Pelas atuais Diretrizes Curriculares Nacionais, a formação do licenciado e do bacharel (graduado), tem se fundado em conhecimentos específicos a cada uma das habilitaçôes e dos campos de intervenção. Para ambos, vejamos que o imperativo na formação desses profissionais é a centralidade nas competências a serem construídas ao longo dos cursos.

David (2003), ao fazer um panorama amplo de como as competências vem ganhando espaço e legitimidade dentro das atuais políticas de formação defende a ideia

de que as competências perspectivadas pelas diretrizes curriculares nacionais possuem, além dos vários significados gerados ou resultantes da esfera cultural e econômica e, ainda que operem restritamente com base no fazer ou no pragmatismo do rendimento educacional, pelo prisma economicista, produz uma eficácia simbólica no interior das relaçóes educativas e sociais envolvidas no processo produtivo do fazer e nas demais relações subjetivas presentes no contexto cultural. (David, 2003, p. 12, grifo do autor)

O uso do termo não é novo dentro das propostas curriculares. De acordo com Dias e Lopes (2003), o termo já era presente na tradição cur- 
ricular, visando o controle comportamental dos professores, partindo do princípio de que bons professores formariam bons alunos. Já nas décadas de 190-70, o enfoque foi individualizado na medida em que se buscava formar atitudes desejáveis no professor. $\mathrm{O}$ que nos chama a atenção é a sua centralidade dentro das diretrizes curriculares para a formaçáo de professores, constituindo, assim, um novo paradigma educacional. Centralizando as competências, o Estado visa, com as novas diretrizes, o controle sobre a formação, o trabalho dos professores, por meio de avaliações periódicas de alcance de metas e resultados (Dias e Lopes, 2003).

Como desdobramento, os professores seráo competentes por mérito, por diminuírem os problemas da escola, por potencializarem as aprendizagens, ganhando status de qualidade e de sucesso frente às demandas postas pelas políticas educacionais e pela realidade em que se inserem. As competências que orientam a formação em geral visam o amoldamento ou adaptação, por meio de atitudes e comportamentos, às demandas postas pela reestruturação produtiva.

Dias e Lopes (2003) nos mostram que pesquisas sobre a eficiência e o desenvolvimento de currículo por competência favoreceram o surgimento da perspectiva de profissionalização da formação docente, assemelhando-se à formação do médico. As ideias de qualidade da educação e de eficiência do trabalho docente seriam associadas ao de perfil profissional bem definido a partir da listagem de competências, sem bases nas especificidades da profissão docente e em sua própria história.

A reorganização da intervenção na Educação Física, dos conteúdos a serem tratados nos cursos de formação e do perfil do profissional que se busca formar, tem alavancado o número de pesquisas acerca da formação em Educação Física nos últimos anos.

No contexto geral, os estudos sobre a formação de professores têmse ampliado nos últimos 20 anos, conforme apontam Shigunov e Maciel (2009). Ainda segundo esses autores, as abordagens referentes a essa área, no Brasil, se intensificaram a partir da década de 1990, ao identificarem a perspectiva do professor pesquisador e professor-reflexivo.

$\mathrm{Na}$ Educação Física, as pesquisas encontram-se focalizadas em diversas vertentes. Correia et al. (2009), ao buscarem a produção do conhecimento sobre a formação de professores em Educação Física nos periódicos científicos, identificaram, na Revista Movimento, tendências importantes nos estudos da área. 
Esses autores mostram as temáticas mais trabalhadas no referido periódico na elaboração do seguinte gráfico, na Figura 1 (Correia et al., 2009, p. 6):

Fig. 1 - Número de textos distribuídos por temáticas abordadas nas pesquisas
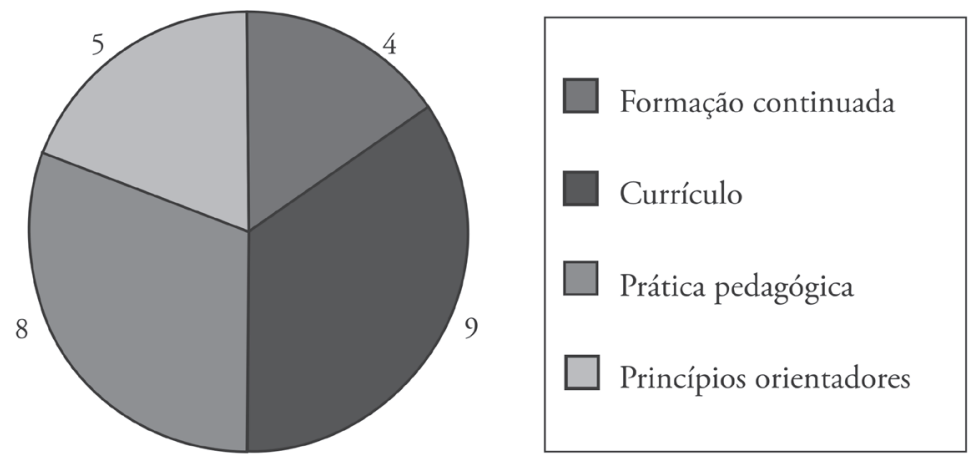

O gráfico acima reflete a preocupação da área frente à temática acerca da formação de professores, num importante periódico científico orientado pelas ciências humanas e sociais. Ainda assim, os autores apontam que a produção do conhecimento na Educação Física sobre a formação de professores ainda é incipiente, representando entre 5\% e 10\% da produção.

Outra evidência da crescente importância da área, atualmente, foi o tema central do Conbrace de 2009: "Formação em Educação Física \& Ciências do Esporte”.

Nossa proposição para o estudo e a análise aprofundada nas questóes que afetam o mundo do trabalho da Educação Física e a formação de seus profissionais é a centralidade do trabalho nesse processo.

Buscamos, ao analisar os estudos anteriores sobre a produção do conhecimento e também sobre a formação de professores em Educação Física, um recorte significativo das tendências nas quais se orientam os estudos e as análises acerca desse importante tema para a área.

Observamos que as pesquisas ou estudos, embora enfoquem características importantes para a melhoria da formação de professores, são, a nosso ver, superficiais ou muito reduzidas para quem procura compreender e aprofundar a análise acerca da formação para o trabalho na Educação Física. 
Nossa proposição para o estudo e a análise aprofundada nas questōes que afetam o mundo do trabalho da Educação Física e a formação de seus profissionais é a centralidade do trabalho nesse processo.

\section{O princípio educativo do trabalho para a Educaçáo Física além dos mundos do trabalho}

As condições de existência humana só são possíveis por meio do trabalho (Marx, 1983). Ao contrário dos animais, que têm suas condiçóes de vida garantidas pela simples adaptação à natureza, o homem adapta a natureza a si, conforme suas necessidades, pois precisa produzir continuamente condiçóes para sua existência. Mas não é qualquer trabalho, ele reveste-se de intencionalidades antecipadas mentalmente (Saviani, 1999). Ou seja:

O trabalhador nada pode criar sem a natureza, sem o mundo exterior sensível. Ela é a matéria na qual o seu trabalho se efetiva, na qual é ativo, e a partir da qual e por meio da qual (o trabalho) produz. Mas como a natureza oferece os meios de vida, no sentido de que o trabalho náo pode viver sem objetos nos quais se exerça, assim também oferece, por outro lado, os meios de vida no sentido mais estrito, isto é, o meio de subsistência física do trabalhador mesmo. (Marx, 2004, p. 81)

Desse modo, a condição de existência dos homens torna-se garantida por meio do trabalho e sua constante intervenção na natureza, produzindo não só as condiçôes materiais e organizacionais da sua vida, como também, no conjunto de conhecimentos (ferramentas, instrumentos, novas formas de transformar a natureza), constituindo, assim, a cultura.

Marx (1983) buscou compreender as formas de organização do trabalho na sociedade capitalista, e revelou-nos um conjunto de novas categorias que vão além do próprio trabalho e que determinam a subfunção dele frente ao modo de produção capitalista. Uma das categorias resultantes da análise da forma de organização do trabalho no capital é a alienação.

À primeira vista, observamos que o trabalho se caracteriza enquanto elemento mediador de transformação da natureza em favor da existência humana. Essa relação, ao mesmo tempo em que torna a natureza modificada, modifica também o próprio homem. 
Pelo modo de produção capitalista, o trabalho é fator de troca e produção, o mesmo passa a ser vendido em forma de mercadoria (Marx, 1996). Sendo assim, temos os vendedores da força de trabalho (os trabalhadores) e os compradores (donos dos meios de produção). Vejamos que, nessa relação de compra e venda da força de trabalho, temos interesses antagônicos no que se refere à apropriação dos bens e conhecimentos produzidos.

Nesse sentido, entendemos que a alienaçáo resume-se no fato de o trabalhador náo se reconhecer como detentor da sua força de trabalho (vendida aos donos dos meios de produção) e náo se apropriar dos produtos resultantes da sua intervenção, mantendo uma relaçẫo de estranhamento a algo que não pertence a si.

Resgatando o trabalho enquanto centralidade da existência humana e o processo de alienação do trabalhador, entendemos que se faz necessária a constante busca dessas categorias como forma de compreensão dos modelos atuais de organização do trabalho, reduzido ao emprego e à profissão, do processo de elaboração e apreensão dos conhecimentos sistematizados.

Somente pela divisão da formação e intervenção em duas modalidades diferentes, percebemos a fragmentaçáo e a constante alienaçấo dos professores frente ao processo e apropriação dos conhecimentos produzidos dentro da Educação Física.

Dessa forma, propomos o resgate da categoria trabalho enquanto princípio educativo na formação de professores de Educação Física por acreditarmos ser esse o caminho para a superação da forma de organização do trabalho no capital.

\section{Consideraçóes finais}

Esse ensaio almejou, de forma sucinta, demonstrar o contexto atual da formação em Educação Física. Como trabalho, modificou-se nos últimos anos devido à crise do capitalismo. Em decorrência das mudanças nas formas de organização do trabalho, observamos o surgimento do bacharel como nova modalidade de formação em Educação Física.

Por fim, identificamos as tendências das pesquisas voltadas à formação em Educação Física e propusemos o resgate da centralidade no trabalho, enquanto princípio educativo na formação dos novos professores. 
Temos como hipótese, neste texto parcial, que as formas de organização, formação e divisão do trabalho na Educação Física têm alienado cada vez mais o trabalhador, refletindo na fragmentação da área.

Neste esboço inicial, defendemos a ideia de uma formação única em Educação Física, com conhecimentos acumulados e legitimados dentro da área. A legitimação desses conhecimentos não deve ficar reduzida à intervenção, mas à apreensão dos conhecimentos acumulados ao longo da história acerca da cultura corporal.

\section{Referências}

CORREIA, A.; NETO, B.; AGUIAR, E. do S. S.; COELHO, H. R. e ARANHA, O. Produçáo do conhecimento sobre formação de professores de Educação Física em periódicos científicos: Análise da Revista Movimento (1994-2008) Congresso Brasileiro de Ciências do Esporte/Congresso Internacional de Ciências do Esporte. 17 jul. 2009.

DAVID, N. Novos ordenamentos legais e a formação de professores em Educação Física: pressupostos de uma nova pedagogia de resultados. (Dissertação de Mestrado) UNICAMP. 2003.

A formação profissional docente em educação física: dicotomias e rupturas no campo da formação e da prática. In: Congresso Goiano de Ciências do Esporte. 2009.

DIAS, R. E; LOPES, A. C. Competências na formação de professores no Brasil: O que (não) há de novo. Educ. Soc. 2003. v. 24, n. 85, p. $1155-$ 1177. Disponível em: <http://www.scielo.br/pdf/es/v24n85/a04v2485. pdf>. Acesso em: 10 dez. 2009.

FURTADO, R. P. Do fitness ao wellnes: os três estágios de desenvolvimento das academias de ginástica. Pensar a Prática, Goiânia, v. 12, n. 1. 2009.

KUENZER, A. Z. A formação de educadores no contexto das mudanças no mundo do trabalho: Novos desafios para as faculdades de educação. Educ. Soc. v. 19, n. 63, p. 105-125. 1998.

MARX, K. O Capital. Tomo 1. São Paulo: Abril Cultural, 1983. 
; ENGELS, F. Manifesto do partido comunista. Petrópolis: Vozes, 1996.

. Manuscritos econômico-filosóficos. São Paulo: Boitempo, 2004.

MÉSZÁROS, I. Para além do capital. Tradução Paulo Cezar Castanheira, Sérgio Lessa. São Paulo: Boitempo, 2006.

SAVIANI, D. Pedagogia histórico-crítica: primeiras aproximaçôes. São Paulo: Cortez/Autores Associados, 1991.

SHIGUNOV NETO, A.; MACIEL, L. Refletindo sobre o passado, o presente e as propostas futuras na formação dos professores. Revista Brasileira de Formação de Professores, América do Norte, v. 1, n. 1, p. 148-161. maio 2009.

Recebido em: 31 maio 2010

Aceito em: 30 jun. 2010 